\title{
Desfolha, população de plantas e precocidade do milho afetam a incidência e a severidade de podridões de colmo
}

\author{
Defoliation, plant population, and earliness of maize affect the incidence \\ and severity of stalk rots
}

\author{
Luiz Eduardo Bassay Blum ${ }^{1}$ Luis Sangoi ${ }^{1}$ Cassandro Vidal Talamini do Amarante ${ }^{1}$ \\ Cristiano João Arioli ${ }^{2}$ Letícia Simone Guimarães ${ }^{2}$
}

\section{RESUMO}

\begin{abstract}
As relações entre fonte e dreno interferem sobre a ocorrência de podridões de colmo na cultura do milho (Zea mays). O estudo foi conduzido em Lages, SC, para avaliar o efeito da desfolha, população de plantas e hibridos sobre as podridões do colmo do milho. $O$ delineamento experimental foi de blocos ao acaso com parcelas sub-subdivididas e três repetições. Os hibridos P32R21 (superprecoce), Premium (precoce) e C333B (tardio) foram testados sem desfolha e com $50 \%$ de desfolha no estágio de espigamento nas populações de 25.000, 50.000, 75.000 e 100.000 plantas ha-1. Avaliaram-se a incidencia e a severidade das podridões do colmo causadas por Colletotrichum graminicola, Diplodia maydis e Fusarium moniliforme. O hibrido P32R21 foi o mais afetado pelos fungos causadores de podridões. Nos híbridos P32R21 e Premium, as plantas desfolhadas foram mais severamente infectadas pelos patógenos do que as intactas. $O$ aumento da população de plantas aumentou a intensidade (incidência ou severidade) de podridões de colmo nas plantas intactas e diminuiu a ocorrência nas desfolhadas.
\end{abstract}

Palavras-chave: Zea mays, Colletotrichum graminicola, Diplodia maydis, Fusarium moniliforme.

\section{ABSTRACT}

The relationship between source and sink interferes on maize (Zea mays) stalk rot occurrence. This study was conducted in Lages, SC, Brazil, to evaluate the effect of defoliation, plant population, and hybrids on the intensity (incidence or severity) of maize stalk rots. The experiment was set in a randomized complete block design (three replications) with a split-split-plot arrangement. The hybrids P32R21 (very early), Premium (early) and C333B (late) were tested without defoliation and with $50 \%$ defoliation on ear formation stage at plant populations of 25,000, 50,000, 75,000, and 100,000 plants ha $a^{-1}$. The incidence and severity of Colletotrichum graminicola, Diplodia maydis and Fusarium moniliforme stalk rots were evaluated. The hybrid P32R21 was the most affected by stalk rots. Defoliation enhanced rots on P32R21 and Premium. Enhancements in plant population increased stalk rots intensity on intact plants but decreased rot occurrence when hybrids were defoliated.

Key words: Zea mays, Colletotrichum graminicola, Diplodia maydis, Fusarium moniliforme.

\section{INTRODUÇÃO}

As podridões do colmo são freqüentes e problemáticas para a produção do milho (Zea mays L.) nas regiões produtoras do Brasil (FERNANDES \& BALMER, 1990; BLUM et al., 1999). Além de debilitarem e reduzirem a produção da cultura, podem ocasionar o acamamento e a morte das plantas (REIS \& CASA, 1996), dificultando a colheita.

Essas podridões são provocadas por diferentes fungos, tais como Colletotrichum graminicola (Ces.) G. W. Wils, Diplodia maydis (Berk.) Sacc. (Sin. Stenocarpella maydis (Berk.) Sutton, Diplodia zea (Schuw.) Lev.), Fusarium moniliforme Sheld., Gibberella zea (Schw.) Petch.,

\footnotetext{
${ }^{1}$ Engenheiro Agrônomo, PhD, Professor do Departamento de Fitotecnia, Centro de Ciências Agroveterinárias, Universidade do Estado de Santa Catarina, CP 281, 88520-000, Lages-SC. E-mail: a2lbb@cav.udesc.br. Autor para correspondência.

${ }^{2}$ Engenheiro Agrônomo, Ex-aluno do curso de Agronomia, Centro de Ciências Agroveterinárias, Universidade do Estado de Santa Catarina, CP 281, 88520-000, Lages-SC.
} 
Physoderma maydis Miy. e Pythium Pringsh. sp. (FERNANDES \& BALMER, 1990; PINTO et al., 1997).

A ocorrência das podridões do colmo é favorecida por alterações nas relações entre fonte e dreno de nutrientes ocorridos durante a fase de enchimento dos grãos (REIS \& CASA, 1996). Fatores que reduzam a fotossíntese e a produção de carboidratos predispõem as plantas às podridões (PINTO et al., 1997). A desfolha durante o florescimento, a população de plantas e a precocidade dos híbridos, alteram a partição de fotoassimilados entre as diferentes estruturas da planta, podendo influenciar na incidência das doenças do colmo do milho (BLUM et al., 1999; BLUM et al., 2001; SANGOI et al., 2000). Híbridos de milho mais antigos são potencialmente mais suscetíveis às podridões de colmo devido a sua menor eficiência fotossintética, principalmente quando cultivados em alta densidade de semeadura (SANGOI et al., 2001b). Os híbridos cultivados atualmente são mais produtivos, resistentes a distúrbios provocados por populações mais elevadas de plantio, deficiência hídrica e, possivelmente, menos sensíveis a doenças (SANGOI et al., 2000).

Há pouca informação conclusiva sobre os efeitos da maior precocidade dos híbridos, do incremento da população de plantas e dos efeitos de restrições ao aparato fotossintético da planta através da desfolha na ocorrência de doenças que afetam o colmo do milho (BLUM et al., 1999; BLUM et al., 2000; BLUM et al., 2001; DENTI \& REIS, 2001). Portanto, o objetivo deste trabalho foi avaliar os efeitos da desfolha, população de plantas e precocidade de híbridos de milho, na ocorrência de podridões de colmo.

\section{MATERIAL E MÉTODOS}

O ensaio foi conduzido em Lages/SC, durante o ano agrícola de 1999/2000. O solo da área experimental é um Nitossolo Vermelho (EMBRAPASOLOS, 1999).

O delineamento experimental foi o de blocos ao acaso com parcelas sub-subdivididas e três repetições. Na parcela principal, foram avaliados três híbridos: P32R21 (superprecoce), Premium (precoce), e C333B (tardio). Cada híbrido foi alojado, nas subparcelas, em populações de 25.000, 50.000, 75.000 e 100.000 plantas ha $^{-1}$. Em cada população, os híbridos foram avaliados, nas sub-subparcelas, com sua área foliar intacta e com a remoção de metade das folhas presentes no espigamento. Cada sub-subparcela foi constituída por cinco linhas (7 metros). Nas sub- subparcelas desfolhadas, removeu-se totalmente as folhas na fração intermediária do colmo, nas quais se localizavam as espigas. Assim, se as plantas apresentavam 14 folhas verdes, removeram-se três folhas acima da espiga superior, a folha índice e três folhas abaixo da mesma. Tais folhas foram removidas quando $50 \%$ das plantas apresentavam-se espigadas (estilo-estigmas visíveis).

O experimento foi conduzido no sistema de semeadura direta, sobre uma cobertura morta de aveia preta (Avena sativa L.), a qual foi dessecada mediante a aplicação de glifosate $\left(1400 \mathrm{~g}\right.$ de i.a. ha $\left.{ }^{-1}\right), 15$ dias antes da semeadura do milho. Foram aplicados na base, $20 \mathrm{~kg}$ de $\mathrm{N}, 70 \mathrm{~kg}$ de $\mathrm{P}_{2} \mathrm{O}_{5}$ e $100 \mathrm{~kg}$ de $\mathrm{K}_{2} \mathrm{O}$. Em cobertura aplicou-se $80 \mathrm{~kg}$ de $\mathrm{N}$ quando as plantas apresentavam cinco folhas expandidas. $\mathrm{Na}$ adubação, consideraram-se os valores de reposição sugeridos pela COMISSÃO DE FERTILIDADE DO SOLO-RS/SC (1995) para a cultura do milho, com perspectivas de obtenção de rendimento de grãos superior a $6 \mathrm{t} \mathrm{ha}^{-1}$.

A semeadura foi efetuada em 11/11/1999, utilizando-se semeadoras manuais e depositando-se três sementes por cova, com espaçamento entre linhas de $75 \mathrm{~cm}$. O espaçamento entre covas adjacentes dentro da linha foi de 53,3, 26,6, 17,8 e 13,3 cm, para as densidades de 25.000, 50.000, 75.000 e 100.000 plantas ha ${ }^{-1}$, respectivamente.

Aplicou-se uma combinação de atrasina (1400g i.a. ha $\left.{ }^{-1}\right)$ e metolachlor (2100g i.a. ha $\left.{ }^{-1}\right)$ sobre a superfície do solo logo após a semeadura para o controle em pré-emergência de plantas daninhas. Quando necessário, efetuou-se controle mecânico pósemergente das invasoras para que as mesmas não interferissem no desenvolvimento do milho. No estádio V4, quatro folhas totalmente expandidas (RITCHIE \& HANWAY, 1993), efetuou-se o desbaste para ajustar a população aos valores definidos em cada tratamento.

A colheita do milho foi feita manualmente, quando todas as folhas da planta estavam senescidas. Durante a colheita, avaliaram-se a incidência e a severidade das podridões (C. graminicola, D. maydis e $\boldsymbol{F}$. moniliforme) nos $30 \mathrm{~cm}$ basais dos colmos de 24 plantas/sub-parcela (12 normais e 12 desfolhadas). A incidência (\%) das podridões em cada sub-sub-parcela foi estimada através da porcentagem de colmos com sintomas de podridão em relação ao total de colmos amostrados. Para avaliação da severidade das podridões, usou-se uma escala de 0 a $3(0=$ sem sintomas nos $30 \mathrm{~cm}$ basais do colmo, $1=<1 / 3 \mathrm{com}$ sintomas, $2=\geq 1 / 3$ e $<1 / 2$ com sintomas e $3=\geq 1 / 2$ com sintomas) (BLUM et al., 2001). Os fungos ( $\boldsymbol{C}$. graminicola, $D$. maydis ou $\boldsymbol{F}$. moniliforme) presentes 
nos colmos infectados foram identificados através da observação de lâminas para microscopia com material fúngico em microscópio óptico e pela observação direta dos colmos em microscópio esterioscópico.

Os dados foram avaliados estatisticamente através de análise de variância e os efeitos dos tratamentos foram testados através do teste F. Quando atingida significância estatística, foi feita a comparação entre médias pelo teste de Duncan em nível de 5\% de probabilidade de erro, para a interação híbrido $\mathrm{x}$ desfolha, em função da severidade e incidência das podridões (C. graminicola, D. maydis e $\boldsymbol{F}$. moniliforme). Para as interações população de plantas $\mathrm{x}$ desfolha e população de plantas $\mathrm{x}$ híbrido, em função da incidência e severidade das podridões, aplicaramse as regressões linear e quadrática (GOMES, 1987).

\section{RESULTADOS E DISCUSSÃO}

A severidade das podridões de colmo causadas por Colletotrichum graminicola, Diplodia maydis ou Fusarium moniliforme foi influenciada significativamente pelas interações híbrido $\mathrm{x}$ desfolha e população de plantas x desfolha (Tabela 1). Resultado semelhante foi obtido com o parâmetro incidência das podridões. Somente no caso da severidade da podridão causada por $\boldsymbol{F}$. moniliforme a interação híbrido $x$ população de plantas foi significativa (Tabela 1).

$\mathrm{Na}$ figura 1 são mostrados resultados da análise de regressão da interação entre população de plantas x desfolha para os dois parâmetros médios de medida de podridão estudados no trabalho. O incremento na população de plantas provocou um aumento significativo da severidade e da incidência de doenças em plantas intactas (Figura 1). Todavia, houve uma tendência de diminuição da severidade e da incidência de podridões com o aumento da população de plantas desfolhadas (Figura 1).

Nas parcelas com plantas desfolhadas e populações mais elevadas (Figura 1), a maior ventilação e a maior penetração de radiação solar criada pela desfolha pode ter desfavorecido parcialmente a incidência das podridões, o que

Tabela 1 - Resumo da análise de variância dos fatores e parâmetros avaliados.

\begin{tabular}{|c|c|c|c|c|c|c|c|c|c|}
\hline \multirow{3}{*}{$\begin{array}{l}\text { Parâmetro } \\
\text { Fator }\end{array}$} & \multicolumn{9}{|c|}{ Incidência de podridão } \\
\hline & \multicolumn{3}{|c|}{ Colletotrichum } & \multicolumn{2}{|c|}{ Diplodia } & \multicolumn{2}{|c|}{ Fusarium } & \multicolumn{2}{|c|}{ Média } \\
\hline & GL & QM & $\mathrm{P}$ & QM & $\mathrm{P}$ & QM & $\mathrm{P}$ & QM & $\mathrm{P}$ \\
\hline $\mathrm{H}$ & 2 & 8481,422 & 0,004 & 115,985 & 0,561 & 5991,778 & 0,003 & 2020,633 & 0,012 \\
\hline PP & 3 & 251,022 & 0,138 & 120,298 & 0,552 & 69,891 & 0,541 & 4,682 & 0,974 \\
\hline $\mathrm{D}$ & 1 & 6217,054 & $<0,001$ & 6025,275 & $<0,001$ & 11353,990 & $<0,001$ & 5625,423 & $<0,001$ \\
\hline $\mathrm{H} \times \mathrm{PP}$ & 6 & 252,291 & 0,105 & 153,634 & 0,356 & 109,478 & 0,260 & 101,554 & 0,226 \\
\hline $\mathrm{H} \times \mathrm{D}$ & 2 & 425,462 & 0,030 & 541,594 & 0,004 & 1109,312 & $<0,001$ & 460,098 & $<0,001$ \\
\hline PP x D & 3 & 934,760 & $<0,001$ & 341,705 & 0,011 & 827,910 & 0,001 & 500,245 & $<0,001$ \\
\hline$H \times P P x D$ & 6 & 124,806 & 0,350 & 48,227 & 0,691 & 122,458 & 0,392 & 64,119 & 0,208 \\
\hline $\mathrm{CV}(\%)$ & \multicolumn{3}{|c|}{${ }^{\mathrm{A}} 10,77 ;{ }^{\mathrm{B}} 15,67 ;{ }^{\mathrm{C}} 20,75$} & \multicolumn{2}{|c|}{${ }^{\mathrm{A}} 12,75 ;{ }^{\mathrm{B}} 22,13 ;{ }^{\mathrm{C}} 23,70$} & \multicolumn{2}{|c|}{${ }^{\mathrm{A}} 9,70 ;{ }^{\mathrm{B}} 15,84 ;{ }^{\mathrm{C}} 26,96$} & \multicolumn{2}{|c|}{${ }^{\mathrm{A}} 8,93 ;{ }^{\mathrm{B}} 13,82 ;{ }^{\mathrm{C}} 15,44$} \\
\hline \multirow[t]{2}{*}{ Parâmetro } & \multicolumn{9}{|c|}{ Severidade de podridão } \\
\hline & \multicolumn{3}{|c|}{ Colletotrichum } & \multicolumn{2}{|c|}{ Diplodia } & \multicolumn{2}{|c|}{ Fusarium } & \multicolumn{2}{|c|}{ Média } \\
\hline Fator & GL & QM & $\mathrm{P}$ & QM & $\mathrm{P}$ & QM & $\mathrm{P}$ & QM & $\mathrm{P}$ \\
\hline $\mathrm{H}$ & 2 & 10,696 & 0,001 & 0,206 & 0,039 & 10,094 & $<0,001$ & 4,554 & 0,001 \\
\hline PP & 3 & 0,016 & 0,902 & 0,009 & 0,939 & 0,043 & 0,397 & 0,013 & 0,825 \\
\hline $\mathrm{D}$ & 1 & 8,515 & $<0,001$ & 2,509 & $<0,001$ & 13,816 & $<0,001$ & 7,521 & $<0,001$ \\
\hline $\mathrm{H} \times \mathrm{PP}$ & 6 & 0,135 & 0,197 & 0,718 & 0,642 & 0,153 & 0,014 & 0,077 & 0,142 \\
\hline H x D & 2 & 2,092 & $<0,001$ & 0,227 & 0,001 & 6,046 & $<0,001$ & 2,065 & $<0,001$ \\
\hline PP x D & 3 & 0,604 & 0,003 & 0,106 & 0,011 & 0,281 & 0,003 & 0,292 & $<0,001$ \\
\hline$H \times P P x D$ & 6 & 0,068 & 0,642 & 0,015 & 0,678 & 0,080 & 0,156 & 0,040 & 0,280 \\
\hline $\mathrm{CV}(\%)$ & \multicolumn{3}{|c|}{${ }^{\mathrm{A}} 10,99 ;{ }^{\mathrm{B}} 21,08 ;{ }^{\mathrm{C}} 31,87$} & \multicolumn{2}{|c|}{${ }^{\mathrm{A}} 12,46 ;{ }^{\mathrm{B}} 41,17 ;{ }^{\mathrm{C}} 33,94$} & \multicolumn{2}{|c|}{${ }^{\mathrm{A}} 10,60 ;{ }^{\mathrm{B}} 19,92 ;{ }^{\mathrm{C}} 29,76$} & \multicolumn{2}{|c|}{${ }^{\mathrm{A}} 10,95 ;{ }^{\mathrm{B}} 20,24 ;{ }^{\mathrm{C}} 24,27$} \\
\hline
\end{tabular}

$\mathrm{H}=$ Híbrido; $\mathrm{PP}=$ população de plantas; $\mathrm{D}=$ Desfolha $\mathrm{GL}=$ graus de liberdade; $\mathrm{QM}=$ quadrado médio; $\mathrm{P}=$ probabilidade calculada; $\mathrm{CV}=$ coeficiente de variação; $\mathrm{A}=\mathrm{CV}$ da repetição; $\mathrm{B}=\mathrm{CV}$ da parcela; $\mathrm{C}=\mathrm{CV}$ da subparcela.

Ciência Rural, v. 33, n. 5, set-out, 2003. 


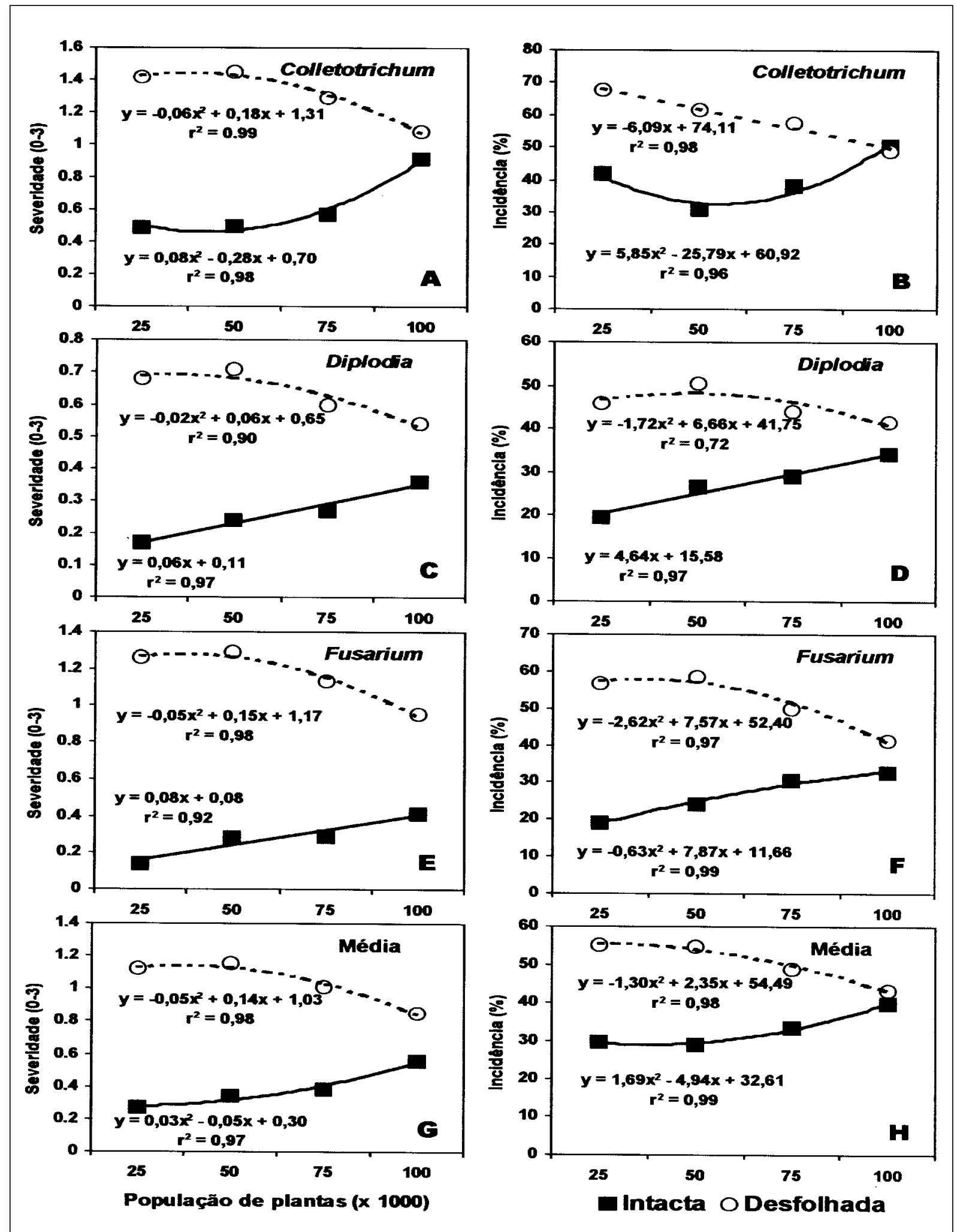

Figura 1 - Influência da população de plantas na (A, C, E e G) severidade e (B, D F e H) incidência das podridões do colmo causadas por Colletotrichum graminicola (A-B), Diplodia maydis (C-B), Fusarium moniliforme (E-F) e média das três podridões (G-H) em híbridos de milho com plantas intactas e desfolhadas.

Ciência Rural, v. 33, n. 5, set-out, 2003. 
possivelmente não ocorreu nos lotes de plantas intactas que foram mais afetados com o aumento da população de plantas. Populações elevadas de plantas aumentam a competição intra-específica por luz, reduzindo a atividade fotossintética da planta (SANGOI, 2001). Isto fragiliza os colmos dao plantao, tornando-os mais suscetíveis ao ataque de patógenos. PANDE et al. (1990) relataram um aumento na incidência da podridão negra (Macrophomina phaseolina (Tassi) Goid.) do colmo do sorgo com o aumento na população de plantas. Estes autores verificaram que a maior incidência da doença estava também associada ao maior déficit hídrico em populações mais elevadas de plantas. SANGOI et al. (2000) também observaram uma maior incidência de doenças do colmo do milho com o aumento da população de plantas.

O híbrido superprecoce P32R21 foi significativamente mais afetado pelas podridões de colmo do que os híbridos mais tardios, com exceção da podridão ocasionada por $\boldsymbol{D}$. maydis (Tabela 2). Quanto maior a precocidade de um híbrido, menor é a sua área foliar (FANCELLI, 2000). Portanto, a redução da área foliar aumenta a contribuição do colmo no suprimento de fotoassimilados ao enchimento de grãos. SANGOI et al. (2001b) observaram que a mobilização de carboidratos do colmo às espigas foi maior no híbrido P32R21 do que nos híbridos Premium e C333-B. Este fato possivelmente contribuiu para aumentar a ocorrência de podridão de colmo no híbrido superprecoce, em relação aos demais genótipos avaliados, tanto nas plantas intactas quantos nas desfolhadas.

Os híbridos Premium (precoce) e C333-B (tardio) foram significativamente menos afetados pelas podridões. O híbrido C333-B foi significativamente menos afetado pela podridão causada por $\boldsymbol{F}$. moniliforme, e o híbrido Premium significativamente menos afetado por C. graminicola (Tabela 2).

As plantas desfolhadas dos híbridos P32R21 e Premium foram significativamente mais afetadas por podridões do que plantas intactas. Por outro lado, não houve diferença significativa quanto à quantidade de doença entre os lotes intactos e desfolhados para o híbrido C333-B (Tabela 2). O híbrido C333-B foi menos severamente afetado pela podridão causada por $\boldsymbol{F}$. moniliforme, independentemente da população de plantas utilizada (Figura 2).

O híbrido tardio C333-B é mais adaptado ao clima tropical do que os híbridos P32R21 e Premium, possuindo maior número de folhas e menor poder de drenagem de carboidratos pelas espigas durante o enchimento dos grãos (SANGOI et al., 2001a). A alta relação entre fonte e dreno do híbrido C333-B contribuiu para que seu colmo fosse menos fragilizado do que o colmo dos híbridos P32R21 e Premium, quando as plantas foram desfolhadas. Esse fato pode justificar parcialmente a razão de não haver diferença significativa entre a ocorrência de podridões em plantas intactas e desfolhadas do híbrido C333-B. PINTER \& KALMAN (1981) relataram uma relação direta e positiva entre a desfolha e a infecção do colmo do milho ocasionada por D. maydis e G. zea. Segundo FAJEMISIN \& HOOKER (1974), plantas de milho com folhas mais severamente infectadas por outras doenças (ferrugens e queimas) que reduzem a sua área fotossinteticamente ativa, são mais afetadas por podridões do colmo ocasionadas por $\boldsymbol{D}$. maydis.

Tabela 2 - Influência da desfolha e de híbridos de milho na severidade e na incidência das podridões do colmo causadas por Fusarium moniliforme, Colletotrichum graminicola e Diplodia maydis.

\begin{tabular}{|c|c|c|c|c|c|c|c|c|}
\hline \multirow{3}{*}{ Híbrido } & \multicolumn{8}{|c|}{ Severidade de podridão $(0-3)^{(1)}$} \\
\hline & \multicolumn{2}{|c|}{ Colletotrichum } & \multicolumn{2}{|c|}{ Diplodia } & \multicolumn{2}{|c|}{ Fusarium } & \multicolumn{2}{|c|}{ Média } \\
\hline & Intacta & Desfolha & Intacta & Desfolha & Intacta & Desfolha & Intacta & Desfolha \\
\hline P32R 21 & $1,04 \mathrm{~B} \mathrm{a}^{(2)}$ & $2,40 \mathrm{~A} \mathrm{a}$ & $0,19 \mathrm{~B} \mathrm{a}$ & $0,74 \mathrm{~A}$ a & $0,44 \mathrm{~B} \mathrm{a}$ & $2,47 \mathrm{~A} \mathrm{a}$ & $0,56 \mathrm{~B} \mathrm{a}$ & $1,86 \mathrm{~A} \mathrm{a}$ \\
\hline C333B & $0,59 \mathrm{~A} \mathrm{~b}$ & $0,84 \mathrm{~A} \mathrm{~b}$ & $0,26 \mathrm{~A} \mathrm{ab}$ & $0,43 \mathrm{~A} \mathrm{~b}$ & $0,14 \mathrm{~A} \mathrm{~b}$ & $0,33 \mathrm{~A} \mathrm{c}$ & $0,33 \mathrm{~A} \mathrm{~b}$ & $0,53 \mathrm{~A} \mathrm{c}$ \\
\hline Premium & $0,23 \mathrm{~B} \mathrm{c}$ & $0,69 \mathrm{~A} \mathrm{~b}$ & $0,33 \mathrm{~B} \mathrm{~b}$ & $0,74 \mathrm{~A} \mathrm{a}$ & $0,26 \mathrm{~B} a b$ & $0,68 \mathrm{~A} \mathrm{~b}$ & $0,27 \mathrm{~B} \mathrm{~b}$ & $0,70 \mathrm{~A} \mathrm{~b}$ \\
\hline & \multicolumn{8}{|c|}{ Incidência de podridão (\%) } \\
\hline P32R21 & $57,83 \mathrm{~B} \mathrm{a}$ & $81,91 \mathrm{~A} \mathrm{a}$ & $22,78 \mathrm{~B}$ a & $51,17 \mathrm{~A} \mathrm{a}$ & $35,06 \mathrm{~B}$ a & $75,39 \mathrm{~A} \mathrm{a}$ & $39,43 \mathrm{~B}$ a & $65,25 \mathrm{~A} \mathrm{a}$ \\
\hline C333B & $41,68 \mathrm{~A} \mathrm{~b}$ & $50,57 \mathrm{~A} \mathrm{~b}$ & $29,12 \mathrm{~A} \mathrm{a}$ & $38,64 \mathrm{~A} \mathrm{~b}$ & $16,56 \mathrm{~A} \mathrm{~b}$ & $30,72 \mathrm{~A} \mathrm{c}$ & $31,65 \mathrm{~A} \mathrm{~b}$ & $40,06 \mathrm{~A} \mathrm{c}$ \\
\hline Premium & $21,35 \mathrm{~B} \mathrm{c}$ & $44,15 \mathrm{~A} \mathrm{~b}$ & $29,64 \mathrm{~B} \mathrm{a}$ & $46,62 \mathrm{~A} \mathrm{a}$ & $28,16 \mathrm{~B}$ a & $49,02 \mathrm{~A} \mathrm{~b}$ & $27,71 \mathrm{~B} \mathrm{~b}$ & $46,51 \mathrm{Ab}$ \\
\hline
\end{tabular}

(1) $0=$ sem sintomas nos $30 \mathrm{~cm}$ basais do colmo; $1=<1 / 3$ com sintomas; $2=\geq 1 / 3 \mathrm{e}<1 / 2$ com sintomas; $3=\geq 1 / 2$ com sintomas.

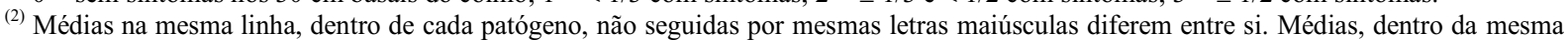
coluna, não seguidas por mesmas letras minúsculas diferem entre si pelo teste de Duncan em nível de $5 \%$ de probabilidade de erro. 


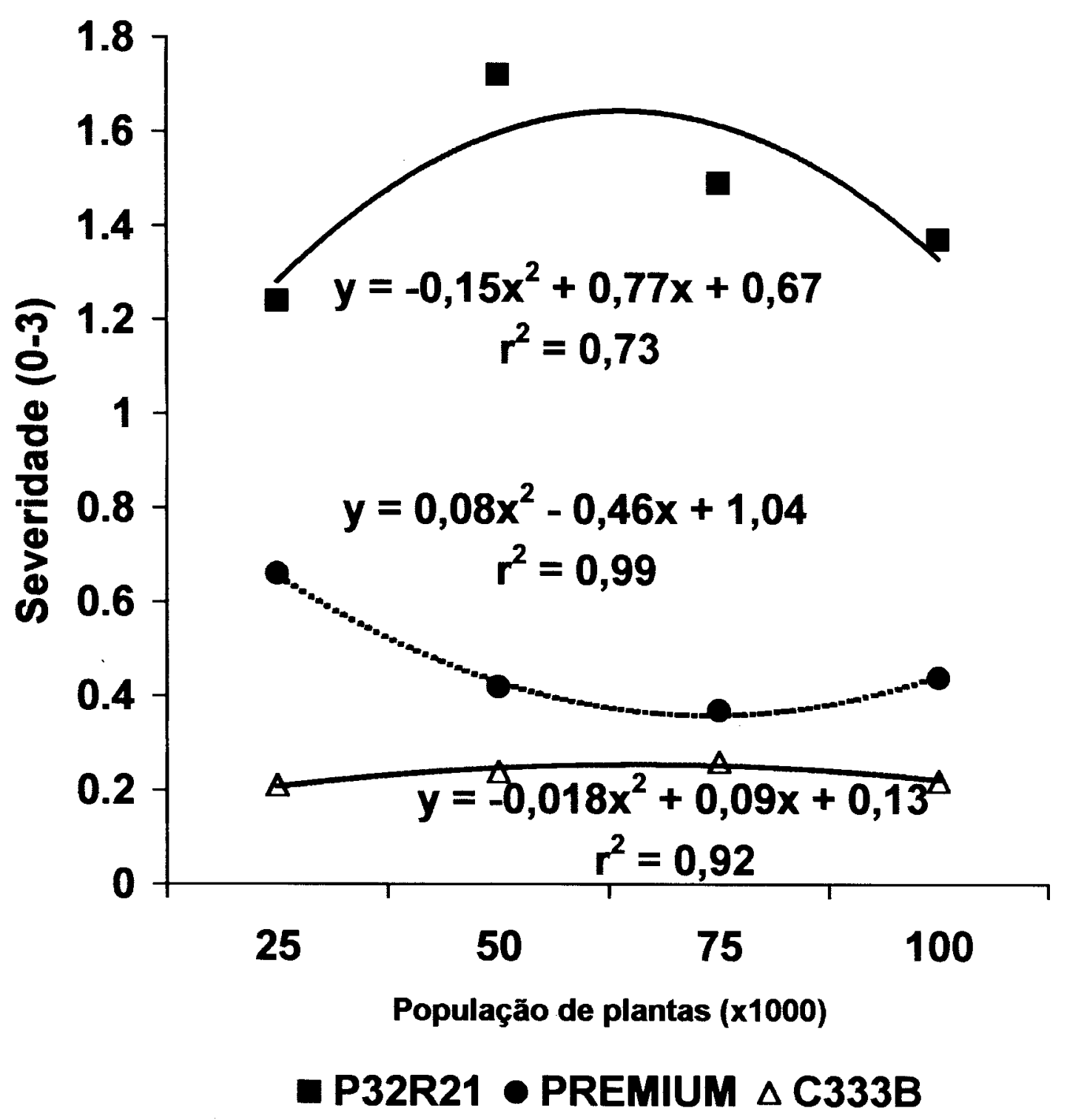

Figura 2 - Influência da população de plantas na severidade da podridão do colmo causada por Fusarium moniliforme nos híbridos P32R21 (superprecoce), Premium (precoce), e C333B (tardio).

Os resultados deste trabalho mostram que modificações entre fonte e dreno através da desfolha, da população de plantas e da precocidade dos híbridos ocasionam alterações na fisiologia da planta, as quais influenciam a intensidade das podridões de colmo do milho.

\section{CONCLUSÕES}

Quanto maior a população de plantas intactas de milho, maior a intensidade de podridões de colmo causadas por Colletotrichum graminicola, Diplodia maydis ou Fusarium moniliforme.
A desfolha aumenta a ocorrência de podridões de colmo em híbrido de ciclo superprecoce (P32R21) e precoce (Premium).

Híbridos com baixa relação entre fonte e dreno (superprecoce), como o P32R21, são mais afetados por podridões de colmo.

\section{REFERÊNCIAS BIBLIOGRÁFICAS}

BLUM, L.E.B. et al. Ocorrência de podridões no colmo do milho: influência da desfolha, população de plantas e híbridos. In: REUNIÃO TÉCNICA CATARINENSE DE MILHO E FEIJÃO, 
3., 2001, Chapecó-SC. Anais... Chapecó : EPAGRI, 2001. p.104108 .

BLUM, L.E.B. et al. Efeito do nitrogênio e de híbridos de milho na severidade da ferrugem comum (Puccinia sorghi) e na incidência de podridões no colmo (Gibberella zea ou Pythium sp.). In: REUNIÃO TÉCNICA CATARINENSE DE MILHO E FEIJÃO, 2., 1999, Lages-SC. Anais... Lages : UDESC/EPAGRI, 1999. p.78-82.

BLUM, L.E.B. et al. Efeito do nitrogênio na intensidade da ferrugem comum e das podridões do colmo de híbridos de milho. Pesquisa Agropecuária Gaúcha, Porto Alegre, v.6, n.2, p.257264, 2000.

COMISSÃO DE FERTILIDADE DO SOLO - RS/SC Recomendações de adubação e calagem para os estados do Rio Grande do Sul e Santa Catarina. 3.ed. Passo Fundo : SBCS-Núcleo Regional Sul; EMBRAPA,CNPT, 1995. 223p.

DENTI, E.A.; REIS, E.M. Efeito da rotação de culturas, da monocultura e da densidade de plantas na incidência das podridões da base do colmo e no rendimento de grãos do milho. Fitopatologia Brasileira, Brasília, v.26, n.3, p.635-639, 2001.

EMBRAPA-CENTRO NACIONAL DE PESQUISA DE SOLOS Sistema brasileiro de classificação de solos. Rio de Janeiro : EMBRAPA, 1999. 412p.

FANCELLI, A.L. Fisiologia da produção e aspectos básicos de manejo para altos rendimentos. In: SANDINI, I.; FANCELLI, A.L. (Ed). Milho: estratégias de manejo para a região sul. Guarapuava : Fundação de Pesquisa Agropecuária, 2000. Cap.7, p.103-116.
FERNANDES, F.T.; BALMER, E. Situação das doenças de milho no Brasil. Informe Agropecuário, Belo Horizonte, n. 165 , p.35-37. 1990 .

GOMES, F.P. A estatística moderna na pesquisa agropecuária. 3.ed. Piracicaba: POTAFOS, 1987. 162p.

PINTO, N.F, J.A.; FERNANDES, F.T.; OLIVEIRA, E. Milho (Zea mays L.) - controle de doenças. In. VALE, F.R.; ZAMBOLIM, L. Controle de doenças de plantas - grandes culturas. Viçosa : Universidade Federal de Viçosa, 1997. V.2, p.821-863.

REIS, E.M.; CASA, R.T. Manual de identificação e controle de doenças de milho. Passo Fundo : Aldeia Norte, 1996. 80p.

RITCHIE, S.W.; HANWAY, J.J. How a corn plant develops. Ames : Iowa State University of Science and Technology, 1993. 26p. (Special Report, 48).

SANGOI, L. Understanding plant density effects on maize groth and development: a fundamental issue to maximize grain yield. Ciência Rural, Santa Maria, v.31, n.1, p.159-168, 2001.

SANGOI, L. et al. Desempenho de híbridos de milho com ciclos contrastantes em função da desfolha e da população de plantas. Scientia Agricola, Piracicaba, v.58, n.2, p.271-276, $2001 \mathrm{a}$.

SANGOI, L. et al. Resposta de híbridos de milho cultivados em diferentes épocas ao aumento na densiade de plantio. In: REUNIÃO TÉCNICA CATARINENSE DE MILHO E FEIJÃO, 3., 2001, Chapecó-SC. Anais... Chapecó : EPAGRI, 2001b. p.48-52.

SANGOI, L. et al. Incidência e severidade de doenças de quatro híbridos de milho cultivados com diferentes densidades de plantas. Ciência Rural, Santa Maria, v.30, n.1, p.17-21, 2000 